\title{
Satisfaction in HER2 Testing among Medical Oncologists - Aiming for Multidisciplinary HER2 Testing in the Philippines
}

\author{
Ivy D. de Dios, ${ }^{1}$ Jerry Y. Tan Chun Bing, ${ }^{1}$ Susano B.Tanael, ${ }^{1}$ Corazon A. Ngelangel ${ }^{1}$ and Ma. Lourdes A. Tiambeng ${ }^{2}$ \\ ${ }^{1}$ Section of Medical Oncology, Department of Medicine, College of Medicine and Philippine General Hospital, University of the Philippines Manila \\ ${ }^{2}$ Department of Medicine, Cardinal Santos Medical Center, Mandaluyong City
}

\begin{abstract}
Introduction. A multidisciplinary approach is essential to optimize patient care. In the practice of oncology, surgeons, medical oncologists, and pathologists are essential for the histology-based diagnosis of cancer patients. In breast cancer, hormone receptor and HER2 positivity are both predictive and prognostic, and so testing for these has been strongly recommended for every newly diagnosed breast cancer patient. A unique but meaningful information that can be provided by medical oncologists, as customers, is their satisfaction to the services (e.g. HER2 testing) and product (e.g. reports) of the pathology laboratory. Any quality initiative effort to improve HER2 testing can also be extended to hormone receptor (ER/PR) testing. This study measures the general satisfaction of medical oncologists practicing in Metro Manila with local HER2 testing services and reports.
\end{abstract}

Methods. This cross-sectional study had survey questionnaires distributed to medical oncologists practising in Metro Manila chosen on the basis of their considerable experience with requesting HER2tests and with the use of anti-HER2 therapy in their management of breast carcinoma patients. Demographics, practice information, rating of satisfaction per laboratory service category, and a checklist of elements of IHC/FISH reports were collected.

Results. 32 medical oncologists participated in the survey, most of whom were from tertiary hospitals. Breast carcinoma cases make up around $26-50 \%$ of cancer cases in their practice. More than half request HER2 testing for their breast cancer patients. Medical oncologists are generally satisfied with the services for IHC and FISH HER2 testing (composite scores $>2$ ) provided by the laboratories. Overall, medical oncologists were very satisfied with diagnostic accuracy and completeness of relevant information in the report. Laboratory services were mostly rated good, with the exception of pathologists' responsiveness to problems and notification of equivocal results. For both IHC and FISH, patient/ physician identification, date of service, specimen identification/ site/ type, results, and interpretation were

Corresponding author: Corazon A. Ngelangel, MD, MS, PhD

Section of Medical Oncology

Department of Medicine

Philippine General Hospital

University of the Philippines Manila

Taft Avenue, Ermita, Manila 1000 Philippines

Tele/Fax: +632 5263775

Email: corazon.ngelangel@gmail.com reported to be included in the reports. However, time to/duration of/type of fixation, method and image analysis method, antibody clone/vendor, and comment that an FDAapproved method was used, were reported missing by the many.

Conclusion. For both IHC and FISH, overall satisfaction was found to be moderately directly correlated with diagnostic accuracy. In a country like the Philippines where quality initiatives of laboratories may still be far from ideal, medical oncologists can demand inclusion of their preferences into assessment processes by laboratories and correct assumptions of laboratory managers as to what element of the services and products they value most. Measurement of customer satisfaction can be integrated into the quality assurance programs of laboratories and corresponding hospitals.

Key Words: satisfaction with HER2 testing, multidisciplinary, breast cancer

\section{Introduction}

Around $20 \%$ of breast cancer patients exhibit amplification of the human epidermal growth factor receptor 2 geneERBB2 (or more commonly known as HER2). HER2 status is proven to be both predictive and prognostic for breast cancer. HER2 positivity is associated with worse clinical outcomes in patients diagnosed with breast cancer and is predictive for response to systemic therapies. HER2 has been proven to be a useful marker for therapeutic decision making. The ASCO Tumor Marker Guidelines panel has recommended the routine testing of HER2 in all newly diagnosed and metastatic breast cancer since $2001 .{ }^{1}$ Also, a guideline on the HER2 testing for breast cancer was already published. ${ }^{2}$

The recommendation implies that multidisciplinary approach is essential to optimize patient care. In the practice of oncology, surgeons, medical oncologists, and pathologists are essential for the histology-based diagnosis of cancer patients. Medical oncologists liaise with surgeons and pathologists in the HER2 testing request of breast tissue sample collected from patients. They have the role of selecting patients for anti-HER2 therapy to maximize clinical benefit and prevent waste of financial resources. They can provide meaningful information for areas of improvement in the management of the laboratory. They can provide customer satisfaction feedback to the services (e.g. HER2 
testing) and product (e.g. reports) of the pathology laboratory. Any quality initiative effort to improve HER2 testing can also be extended to hormone receptor (ER/PR) testing.

The surgical pathology report is the final product of the surgical pathology laboratory and the customers receiving and assessing the quality of the report are the physicians and patients. Elements necessary for quality in surgical pathology reports include accuracy, timeliness, and completeness. Satisfaction with the report is often based on elements that are unique to the customer, such as expectations and individual perceptions. These factors are not as easily addressed because of the multiplicity and uniqueness of these expectations, which can vary with various physician customers. This study measures general satisfaction of medical oncologists practicing in Metro Manila with HER2 testing service and report.

\section{Methods}

This is a cross-sectional study which distributed survey questionnaires to medical oncologists practising in hospitals in Metro Manila. The medical oncologists were chosen on the basis of their considerable experience with requesting HER2 studies and with the use of anti-HER2 therapy in their management of breast carcinoma patients. Demographics and practice information were collected. The hospitals were Cardinal Santos, Manila Doctor's Hospital, Medical City, National Kidney and Transplant Institute and Saint Luke's Medical Center. The hospitals were coded by capital letters in the report.

The questionnaires consist of two parts, namely, rating of satisfaction per laboratory service category and a checklist of elements of IHC/FISH reports. The survey asked the medical oncologists to rate overall satisfaction and specific laboratory services (i.e., diagnostic accuracy, timeliness, accessibility to staff, staff courtesy, tumor board conferences). Laboratory services were graded as excellent, good, average, poor or not applicable. The second part of the survey asked the medical oncologists to check the elements that they think are included in the IHC and FISH reports that they worked with. The report by the medical oncologists was compared to the corresponding items at the actual laboratory report from the hospital.

The data were tabulated and analyzed using statistical analysis. Satisfaction scores were calculated. The overall satisfaction score as the composite measure of satisfaction was used, according to Jones et $\mathrm{al}^{3}$, modified in this study (no below-average category) with 4 being the highest score:

Overall satisfaction score: (No. of Excellent Ratings x 4) $+($ No. of Good Ratings x 3) + (No. of Average Ratings x 2) + (No. of Poor Ratings x 1)/Total No. of Ratings (1-4) for Overall Satisfaction with Laboratory Services and specific laboratory service category.
Associations between overall satisfaction score and variables such as diagnostic accuracy and timeliness, and those between the medical oncologists' perception of completeness and the percentage of elements perceived to be included in the reports were evaluated by calculating the Spearman correlation coefficient for independent variables. Actual local IHC and FISH reports were also evaluated. An item is considered included if $\geq 50 \%$ of the medical oncologists stated that the item is included in the reports they received or if the item is identified in $\geq 50 \%$ of the actual reports.

\section{Results and Discussion}

\section{Demographics and Practice Characteristics of Medical Oncologists}

A total of 32 medical oncologists fulfilling the eligibility criteria practising in Metro Manila (out of total 37; the 5 being study staff) participated in the survey (Table 1). Most practised in tertiary hospitals. Around $26-50 \%$ of the cases managed by the medical oncologists were breast cancer. More than half requested HER2 testing for nearly all of their breast cancer patients. The surgical-pathology laboratories of hospitals $\mathrm{A}$ and $\mathrm{B}$ were the main laboratories where specimens were sent for both IHC and FISH HER2 testing (Table 2).

Table 1. Demographic profile

\begin{tabular}{lc}
\hline & Frequency (\%) \\
\hline Sex & \\
Male & $14(44 \%)$ \\
$\quad$ Female & $18(56 \%)$ \\
Age & \\
$30-39$ & $8(25 \%)$ \\
$40-49$ & $16(50 \%)$ \\
$50-59$ & $7(22 \%)$ \\
60 years and above & $1(3 \%)$ \\
Main clinical practice setting & \\
Tertiary hospital, MM & $30(94 \%)$ \\
Others & $1(3 \%)$ \\
Not specified & 1 \\
Estimated proportion of breast CA patients & \\
treated/month & \\
$<10 \%$, & $1(3 \%)$ \\
$10-25 \%$ & $7(22 \%)$ \\
$26-50 \%$ & $16(50 \%)$ \\
$51-75 \%$ & $5(16 \%)$ \\
$>75 \%$ & $3(9 \%)$ \\
Estimated proportion of breast CA patients for & \\
whom HER2 testing is requested per month & \\
$<10 \%$, & \\
$10-25 \%$ & $6(19 \%)$ \\
$26-50 \%$ & \\
$51-75 \%$ & $3(13 \%)$ \\
$\quad$ Not specified & 0 \\
\hline
\end{tabular}


Table 2. Laboratories for IHC and FISH HER2 testing

\begin{tabular}{ccc}
\hline \multirow{2}{*}{ Laboratories } & \multicolumn{2}{c}{ Percentage of requesting medical oncologists } \\
\cline { 2 - 3 } & IHC & FISH \\
\hline A & $41 \%(13)$ & $63 \%(20)$ \\
B & $19 \%(6)$ & $22 \%(7)$ \\
C & $9 \%(3)$ & 0 \\
D & $6 \%(2)$ & $6 \%(2)$ \\
E & $3 \%(1)$ & $3 \%(1)$ \\
F & $3 \%(1)$ & \\
Not specified & $19 \%$ & $6 \%(2)$ \\
\hline
\end{tabular}

\section{Satisfaction with Laboratory Services for IHC and FISH HER2 Testing}

Medical oncologists were generally satisfied with the services provided by the laboratories doing IHC and FISH HER2 testing (Table 3). Overall, medical oncologists were very satisfied with diagnostic accuracy and completeness of relevant information in the report. This is consistent with the survey of Zarbo et $\mathrm{al}^{4}$ and Jones et $\mathrm{al}^{3}$. Laboratory services were mostly rated good, with the exception of pathologists' responsiveness to problems and notification of equivocal results, which reflected poor communication between the pathologists and the oncologists. This was consistent with findings from international surveys where factors related to poor communication such as timeliness, communication of relevant information and notification of abnormal results earned the lowest satisfaction scores. ${ }^{3-5}$ Ongoing communication between the pathologists and the medical oncologists will decrease the level of dissatisfaction and will enhance the pathologist's role as a consultant. Timeliness of reports incurred an acceptable level of satisfaction. The usual turnaround time for IHC and FISH reports was 7-10 days, similar to international standards.
A lower level of satisfaction was seen among medical oncologists with respect to teaching conferences and tumor board presentations, with some indicating having no experience with such. However, institutions without pathology resident training were associated with a higher percentage of excellent/good ratings for communication of relevant information, timeliness and notification of abnormal results. ${ }^{6}$ This was because teaching was associated with significant delays in reporting.

A high level of satisfaction was seen with completeness of the report and notably with diagnostic accuracy and timeliness of FISH HER2 testing, as compared to IHC testing (Table 3).

Tables 4-6 show the scores for overall satisfaction, diagnostic accuracy and timeliness for IHC and FISH HER2 testing per laboratory of choice. For IHC, laboratories D, E and $\mathrm{F}$ garnered the highest composite scores, though it can be noted that fewer oncologists sent their specimens to these laboratories. With respect to timeliness however, oncologists were more satisfied with laboratories B, C and D while laboratory E fared poorly.

Composites scores were higher for FISH than IHC HER2 testing. A probable reason for this was that FISH is known to be already confirmatory, and results of FISH testing whether negative or positive tend to be fully and immediately accepted. In contrast to IHC, the results of are still subject to confirmation with FISH. Another probable reason is the inclusion of images in the report. Nakhleh et $\mathrm{al}^{5}$ noted that the inclusion of images in the report was associated with a higher level of satisfaction.

Table 3. Ratings of laboratory services

\begin{tabular}{|c|c|c|c|c|c|c|}
\hline Laboratory service category & $\begin{array}{l}\text { Excellent, } \\
\% \text { (No.)* }^{*}\end{array}$ & $\begin{array}{c}\text { Good, } \\
\% \text { (No.) }\end{array}$ & $\begin{array}{c}\text { Average, } \\
\% \text { (No.) }\end{array}$ & $\begin{array}{c}\text { Poor, } \\
\% \text { (No.) }\end{array}$ & $\begin{array}{c}\text { Not Applicable } \\
\%, \text { (No.) }\end{array}$ & $\begin{array}{c}\text { Composite } \\
\text { score }^{*}\end{array}$ \\
\hline Overall satisfaction level - IHC HER2 testing & $12.5 \%(4)$ & $59.4 \%(19)$ & $25 \%(8)$ & $3.1 \%(1)$ & $0 \%(0)$ & 2.81 \\
\hline Overall satisfaction level - FISH HER2 testing & $37.5 \%(12)$ & $50 \%(16)$ & $9.4 \%(3)$ & $0 \%$ & $3.1 \%(1)$ & 3.29 \\
\hline Diagnostic accuracy - IHC HER2 testing & $9.4 \%(3)$ & $59.4 \%(19)$ & $28.1 \%(9)$ & $3.1 \%(1)$ & $0 \%$ & 2.75 \\
\hline Diagnostic accuracy - FISH HER2 testing & $37.5 \%(12)$ & $53.1 \%(17)$ & $6.3 \%(2)$ & $0 \%$ & $3.1 \%(1)$ & 3.32 \\
\hline Completeness of relevant information in the report & $28.1 \%(9)$ & $65.6 \%(21)$ & $6.3 \%(2)$ & $0 \%$ & $0 \%$ & 3.22 \\
\hline Timeliness of IHC report & $25 \%(8)$ & $50 \%(16)$ & $12.5 \%(4)$ & $12.5 \%(4)$ & $0 \%$ & 2.88 \\
\hline Timeliness of FISH report & $25 \%(8)$ & $46.9 \%(15)$ & $18.8 \%(6)$ & $6.3 \%(2)$ & $3.1 \%(1)$ & 2.94 \\
\hline Tumor board presentations of HER2 testing issues & $3.1 \%(1)$ & $34.4 \%(11)$ & $25 \%(8)$ & $15.6 \%(5)$ & $21.9 \%(7)$ & 2.32 \\
\hline Teaching conferences or courses on HER2 testing & $0 \%(0)$ & $37.5 \%(12)$ & $28.1 \%(9)$ & $12.5 \%(4)$ & $21.9 \%(7)$ & 2.32 \\
\hline Pathologists accessibility for paraffin block & $9.4 \%(3)$ & $53.1 \%(17)$ & $25 \%(8)$ & $9.4 \%(3)$ & $3.1 \%(1)$ & 2.65 \\
\hline Pathologists responsiveness to problems of HER2 testing & $15.6 \%(5)$ & $37.5 \%(12)$ & $40.6 \%(13)$ & $6.3 \%(2)$ & $0 \%(0)$ & 2.62 \\
\hline Overall quality of professional interaction & $15.6 \%(5)$ & $46.9 \%(15)$ & $21.9 \%(7)$ & $12.5 \%(4)$ & $3.1 \%(1)$ & 2.68 \\
\hline Courtesy of technical and secretarial staff who answer phones & $9.4 \%(3)$ & $46.9 \%(15)$ & $28.1 \%(9)$ & $9.4 \%(3)$ & $6.3 \%(2)$ & 2.60 \\
\hline Notification of unsuitable samples for HER2 testing & $12.5 \%(4)$ & $43.8 \%(14)$ & $28.1 \%(9)$ & $9.4 \%(3)$ & $6.3 \%(2)$ & 2.63 \\
\hline Notification of significant equivocal results & $15.6 \%(5)$ & $28.1 \%(9)$ & $34.4 \%(11)$ & $15.6 \%(5)$ & $6.3 \%(2)$ & 2.45 \\
\hline Clarity and format of paper reports & $15.6 \%(5)$ & $59.4 \%(19)$ & $12.5 \%(4)$ & $9.4 \%(3)$ & $3.1 \%(1)$ & 2.84 \\
\hline
\end{tabular}

${ }^{*}$ No. $=$ aggregate number ; ${ }^{* *}$ Composite scores calculated according to Jones et al. (2009), score of 4 as the highest. 
Table 4. Overall satisfaction in HER2 testing per laboratory of preference

\begin{tabular}{|c|c|c|c|c|c|c|}
\hline \multirow[b]{2}{*}{ Laboratory } & \multirow[b]{2}{*}{$\begin{array}{c}\text { Totat } \\
\text { number of } \\
\text { respondents, } \\
\mathbf{n}\end{array}$} & \multicolumn{4}{|c|}{ Aggregate number of ratings } & \multirow[b]{2}{*}{$\begin{array}{c}\text { Composite } \\
\text { score * }\end{array}$} \\
\hline & & 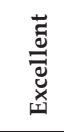 & $\begin{array}{l}\text { D } \\
0 \\
0\end{array}$ & 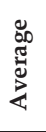 & 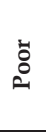 & \\
\hline \multicolumn{7}{|l|}{ IHC } \\
\hline A & 3 & 0 & 2 & 1 & 0 & 2.67 \\
\hline B & 13 & 2 & 7 & 4 & 0 & 2.85 \\
\hline C & 6 & 2 & 2 & 1 & 1 & 2.83 \\
\hline D & 2 & 0 & 2 & 0 & 0 & 3.00 \\
\hline $\mathrm{E}$ & 1 & 0 & 1 & 0 & 0 & 3.00 \\
\hline F & 1 & 0 & 1 & 0 & 0 & 3.00 \\
\hline \multicolumn{7}{|l|}{ FISH } \\
\hline B & 20 & 8 & 11 & 1 & 0 & 3.35 \\
\hline C & 7 & 3 & 2 & 2 & 0 & 2.86 \\
\hline D & 2 & 0 & 2 & 0 & 0 & 3.00 \\
\hline $\mathrm{E}$ & 1 & 0 & 1 & 0 & 0 & 3.00 \\
\hline
\end{tabular}

${ }^{*}$ Composite score calculated according to Jones et al (2009), score of 4 as the highest.

Table 5. Diagnostic accuracy of HER2 testing per laboratory of preference

\begin{tabular}{|c|c|c|c|c|c|c|}
\hline \multirow[b]{2}{*}{ Laboratory } & \multirow[b]{2}{*}{$\begin{array}{c}\text { Totat } \\
\text { number of } \\
\text { respondents, } \\
\mathbf{n}\end{array}$} & \multicolumn{4}{|c|}{ Aggregate number of ratings } & \multirow[b]{2}{*}{$\begin{array}{c}\text { Composite } \\
\text { score }\end{array}$} \\
\hline & & 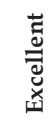 & T & 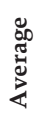 & : & \\
\hline \multicolumn{7}{|l|}{ IHC } \\
\hline A & 3 & 0 & 2 & 1 & 0 & 2.67 \\
\hline $\mathrm{B}$ & 13 & 1 & 7 & 5 & 0 & 2.69 \\
\hline $\mathrm{C}$ & 6 & 1 & 3 & 1 & 1 & 2.67 \\
\hline $\mathrm{D}$ & 2 & 1 & 1 & 0 & 0 & 3.50 \\
\hline $\mathrm{E}$ & 1 & 0 & 1 & 0 & 0 & 3.00 \\
\hline F & 1 & 0 & 1 & 0 & 0 & 3.00 \\
\hline \multicolumn{7}{|l|}{ FISH } \\
\hline B & 20 & 9 & 11 & 0 & 0 & 3.45 \\
\hline $\mathrm{C}$ & 7 & 1 & 4 & 2 & 0 & 2.57 \\
\hline $\mathrm{D}$ & 2 & 1 & 1 & 0 & 0 & 3.50 \\
\hline $\mathrm{E}$ & 1 & 0 & 1 & 0 & 0 & 3.00 \\
\hline
\end{tabular}

*Composite score calculated according to Jones et al (2009).

Table 6. Timeliness in IHC HER2 testing per laboratory of preference

\begin{tabular}{|c|c|c|c|c|c|c|}
\hline \multirow[b]{2}{*}{ Laboratory } & \multirow[b]{2}{*}{$\begin{array}{c}\text { Total } \\
\text { number of } \\
\text { respondents, } \\
\mathbf{n}\end{array}$} & \multicolumn{4}{|c|}{ Aggregate number of ratings } & \multirow[b]{2}{*}{$\begin{array}{c}\text { Composite } \\
\text { score * }\end{array}$} \\
\hline & & $\begin{array}{l}\overrightarrow{0} \\
\stackrel{\overrightarrow{0}}{\bar{\Xi}} \\
\text { 爻 }\end{array}$ & ד & 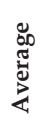 & $\stackrel{\circ}{\circ}$ & \\
\hline \multicolumn{7}{|l|}{ IHC } \\
\hline A & 3 & 1 & 0 & 1 & 1 & 2.33 \\
\hline B & 13 & 3 & 7 & 2 & 1 & 2.92 \\
\hline $\mathrm{C}$ & 6 & 2 & 3 & 1 & 0 & 3.17 \\
\hline $\mathrm{D}$ & 2 & 2 & 0 & 0 & 0 & 4.00 \\
\hline $\mathrm{E}$ & 1 & 0 & 0 & 0 & 1 & 1.00 \\
\hline F & 1 & 0 & 1 & 0 & 0 & 3.00 \\
\hline \multicolumn{7}{|l|}{ FISH } \\
\hline B & 20 & 5 & 10 & 4 & 1 & 2.95 \\
\hline $\mathrm{C}$ & 7 & 2 & 3 & 2 & 0 & 3.00 \\
\hline $\mathrm{D}$ & 2 & 1 & 1 & 0 & 0 & 3.50 \\
\hline $\mathrm{E}$ & 1 & 0 & 0 & 0 & 1 & 1.00 \\
\hline
\end{tabular}

Correlation between overall satisfaction and both diagnostic accuracy and timeliness for IHC and FISH were calculated using the Spearman rank correlation coefficient test for independence (Table 7). For both IHC and FISH, overall satisfaction was found to be moderately directly correlated with diagnostic accuracy. The strength of correlation between overall satisfaction and timeliness was lower compared to the correlation between overall satisfaction and diagnostic accuracy. This was consistent with the lower composite scores for timeliness. This indicated that overall satisfaction was more strongly determined by the report's diagnostic accuracy rather than timeliness.

Table 7. Correlation of overall satisfaction with diagnostic accuracy and timeliness

\begin{tabular}{lcc}
\hline \multicolumn{1}{c}{ IHC HER2 Testing } & $\begin{array}{c}\text { Spearman } \\
\text { correlation } \\
\text { coefficient }\end{array}$ & Test of Ho \\
\hline $\begin{array}{l}\text { Overall satisfaction and diagnostic } \\
\text { accuracy }\end{array}$ & 0.7787 & Prob $>|t|=0.0000$ \\
$\begin{array}{l}\text { Overall satisfaction and timeliness } \\
\text { FISH HER2 Testing } \\
\begin{array}{l}\text { Overall satisfaction and diagnostic } \\
\text { accuracy }\end{array}\end{array}$ & 0.4782 & Prob $>|t|=0.0056$ \\
Overall satisfaction and timeliness & 0.7970 & Prob $>|t|=0.0000$ \\
\hline
\end{tabular}

\section{Elements of IHC and FISH reports}

Tables 8 list the commonly included and commonly missed elements in IHC and FISH reports, respectively. For both IHC and FISH, patient and physician identification, date of service, specimen identification and site and type, results and interpretation were reported by many to be included in the reports, while time to/duration of/type of fixation, method and image analysis method, antibody clone/vendor and comment that an FDA-approved method was used were reported to be missing.

Table 9 shows the association between the medical oncologists' rating of the completeness of the report with the number of elements reported to be included in the local IHC report. A very low negative Spearman correlation coefficient indicates that there was a very weak inverse relationship between the perceived completeness and the proportion or percentage of elements perceived to be included in the IHC HER2 report. For FISH the computed correlation coefficient was likewise very low but positive, indicating a very weak direct relationship between the perceived completeness and percentage of elements perceived to be included in the FISH HER2 report. 
Table 8. Elements included in the IHC and FISH reports.

\begin{tabular}{|c|c|c|c|c|}
\hline \multirow[b]{2}{*}{ Elements of Reports } & \multicolumn{2}{|c|}{ IHC Reports } & \multicolumn{2}{|c|}{ FISH Reports } \\
\hline & $\begin{array}{l}\text { According to } \\
\text { Medical Oncologists }\end{array}$ & $\begin{array}{l}\text { Based on Actual } \\
\text { Report Forms }\end{array}$ & $\begin{array}{l}\text { According to } \\
\text { Medical Oncologists }\end{array}$ & $\begin{array}{l}\text { Based on Actual } \\
\text { Report Forms }\end{array}$ \\
\hline Patient identification & Yes & Yes & Yes & Yes \\
\hline Physician identification & Yes & Yes & Yes & Yes \\
\hline Date of service & Yes & Yes & Yes & Yes \\
\hline Specimen identification & Yes & Yes & Yes & Yes \\
\hline Specimen site and type & Yes & Yes & Yes & Yes \\
\hline Specimen fixative type & No & No & No & No \\
\hline Time to fixation & No & No & No & No \\
\hline Duration of fixation & Yes & No & No & No \\
\hline Antibody clone/vendor & No & No & Yes & NA \\
\hline Probe identification & NA & NA & NS & Yes \\
\hline Method used (test/vendor and if FDA approved) & Yes & NR & No & No \\
\hline Image analysis method (if used) & No & No & No & No \\
\hline $\begin{array}{l}\text { Controls (high protein expression, low-level protein expression, negative } \\
\text { protein expression, internal) }\end{array}$ & Yes & NR & Yes & Yes \\
\hline Adequacy of sample for evaluation & No & No & No & No \\
\hline $\begin{array}{l}\text { Results: percentage of invasive tumor cells exhibiting complete membrane } \\
\text { staining }\end{array}$ & Yes & Yes & Yes & NA \\
\hline Results: uniformity of staining: present/absent & Yes & NR & No & NA \\
\hline Results: homogeneous, dark circumferential pattern: present/absent & Yes & NR & Yes & NA \\
\hline Results :average number of CEP 17 chromosome probes/nucleus & NA & NA & NS & No \\
\hline Results: average number of HER2 signals/nucleus & NA & NA & NS & No \\
\hline Interpretation: positive (for HER2 protein expression) & No & Yes & Yes & Yes \\
\hline Interpretation: equivocal (FISH will be done and reported) & Yes & Yes & No & Yes \\
\hline Interpretation: negative (for HER2 protein expression) & Yes & Yes & Yes & Yes \\
\hline Interpretation: not interpretable & No & No & No & Yes \\
\hline $\begin{array}{l}\text { Interpretation: a statement if IHC is being done because of problems with } \\
\text { assays or results }\end{array}$ & NA & NA & NS & No \\
\hline Comment: statement that FDA approved method is used & No & No & No & No \\
\hline $\begin{array}{l}\text { Comment: statement that method has been modified, including } \\
\text { modifications that were made and the changes that have been validated }\end{array}$ & Yes & Yes & No & No \\
\hline $\begin{array}{l}\text { Comment: if not FDA-approved, or an FDA approved test has been } \\
\text { modified, a clear statement is made that the lab reporting results takes } \\
\text { responsibility for test performance }\end{array}$ & Yes & Yes & No & No \\
\hline
\end{tabular}

Table 9. Completeness of relevant information in report and mean percentage of elements perceived by medical oncologists to be included in IHC HER2 report.

\begin{tabular}{|c|c|c|c|}
\hline \multirow{2}{*}{$\begin{array}{l}\text { Completeness of } \\
\text { information }\end{array}$} & \multirow{2}{*}{$\begin{array}{l}\text { Frequency, } \\
\text { n }\end{array}$} & \multicolumn{2}{|c|}{$\begin{array}{l}\text { Percentage of elements } \\
\text { reported as included }\end{array}$} \\
\hline & & Mean & Standard Deviation \\
\hline \multicolumn{4}{|l|}{ IHC Report } \\
\hline Excellent & 9 & 59.9 & 19.3 \\
\hline Good & 21 & 55.9 & 18.1 \\
\hline Average & 2 & 47.8 & 24.6 \\
\hline \multicolumn{4}{|l|}{ FISH Report } \\
\hline Excellent & 8 & 57.06 & 14.59 \\
\hline Good & 21 & 58.61 & 16.55 \\
\hline Average & 2 & 45.65 & 46.17 \\
\hline $\begin{array}{l}\text { IHC: Spearman } \\
\text { completeness and pe } \\
\text { HER2 report are in } \\
\text { correlation coefficien }\end{array}$ & $\begin{array}{l}\text { correlatio } \\
\text { ntage of ele } \\
\text { pendent }(\mathrm{Pr} \\
=-0.0821 ; \mathrm{Tes}\end{array}$ & $\begin{array}{l}\text { efficient } \\
\text { perceiv } \\
\mathrm{tl}=0 . \\
\text { Ho: (Prol }\end{array}$ & $\begin{array}{l}0.0592 ; \text { Test of Ho: } \\
\text { be included in FISH } \\
\text { FISH: Spearman } \\
=0.6552)\end{array}$ \\
\hline
\end{tabular}

The results agree with findings of Nakhleh $^{6}$ with diagnostic accuracy as one of the most important source of satisfaction. These results have several implications. Rating of completeness by the majority was generally better than average but the percentages of elements included in the reports were only at least half of the recommended number of elements (as enumerated by the ASCO/CAP guidelines). This suggests that medical oncologists generally deemed local HER2 reports adequate enough though in fact lacking some elements as recommended by the guidelines. The very weak association between the perception of completeness and the perception of the elements that were included in the report implied that the perception of completeness may not depend on the "actual" completeness of the report (almost all, if not all, the elements being present) but may in fact depend on the presence of the elements commonly deemed to be present (Table 8). This is consistent with Nakhleh's observation $^{6}$ that while there are many elements that when combined add up to a quality laboratory, clinician satisfaction is also based on the additional factor of expectations. 


\section{Summary}

Physician and patient satisfaction is an important measure of quality because it gives insight into the customer's (physician or patient) perception of the laboratory. While there are many ingredients that add up to a quality laboratory, customer expectations is an additional factor in clinician satisfaction. Therefore, in addition to managing and monitoring all the elements of quality, the pathologist must also manage clinician expectations and make sure that these are realistic. It becomes important then for the pathologist to obtain feedback, without which, some problems may never be identified.

In this Philippine study, overall satisfaction with IHC/ FISH HER2 testing was found to be moderately directly correlated with diagnostic accuracy. The strength of correlation between overall satisfaction and timeliness was lower compared to the correlation between overall satisfaction and diagnostic accuracy. This was consistent with the lower composite scores for timeliness. This indicated that overall satisfaction was more strongly determined by the report's diagnostic accuracy rather than timeliness. The elements commonly included for both IHC and FISH were patient/ physician identification, date of service, specimen identification/ site/ type, and results/ interpretation.

\section{References}

1. Bast RC Jr, Ravdin P, Hayes DF, et al. 2000 update of recommendations for the use of tumor markers in breast and colorectal cancer: clinical practice guidelines of the American Society of Clinical Oncology. J Clin Oncol. 2001; 19(6):1865-78.

2. Wolff AC, Hammond ME, Schwartz JN, et al. American Society of Clinical Oncology/ College of American Pathologists guideline recommendations for human epidermal growth factor receptor 2 testing in breast cancer. Arch Pathol Lab Med. 2007; 131(1):18-43.

3. Jones BA, Bekeris LG, Nakhleh RE, et al. Physician satisfaction with clinical laboratory services: a College of American Pathologists Q-Probes study of 138 institutions. Arch Pathol Lab Med. 2009; 133(1):38-43.

4. Zarbo RJ. Determining customer satisfaction in anatomic pathology. Arch Pathol Lab Med. 2006; 130(5):645-9.

5. Nakhleh RE, Souers R, Ruby SG. Physician satisfaction with surgical pathology reports: a 2 year College of American Pathologists Q-Track Study. Arch Pathol Lab Med.2008; 132(11):1719-22.

6. Nakhleh RE. What is quality in surgical pathology? J Clin Pathol. 2006; 59(7):669-72. 